3 焚祺诚, 刘若新. 汉诺坝玄武岩中高温麻粒岩捕虏体. 科学通报, 1996, 41(3)：235 238

4 翟明国, 郭敬辉, 阎月华, 等. 中国华北太古宙高压基性麻粒岩的发现及其初步研究. 中国科学，B 辑，1992(12)：1 $325 \sim 1330$

5 刘 良, 周鼎武, 董云鹏, 等. 东秦岭松树沟高压变质基性岩石及其退变质作用的 PTt 演化轨迹. 岩石学报, 1995, 11 (2) : $127 \sim 136$

6 Mottana A. Crystal_chemical evolution of garnet and omphacite microprobe analysis, its bearing on the the classification of $e^{-}$ clogites. Lithos, 1986, 19: 171 186

7 O' Reilly S Y, Griffin W L. A xenolith_derived geotherm for southeastern Australia and its geological implications. Tectonophysics, 1985, 111: 41 63

8 Xu X, O'Reilly S Y, Griffin W L, et al, The nature the Cenozoic lithosphere at Nushan, eastern China. In: M artin F J F, Zhong S L, eds. Mantle Dynamics and Plate Interactions in East Asia, Am Geophy Union, 1998 (in press)

9 Brey G P, Kohler T. Geothermobarometry in four_phase lherzolites II. new thermobarometers, and practical assessment of existing thermobarometers. J Petrol, 1990, 31(6): $1353 \sim 1378$

10 广东省地质矿产局. 广东省区域地质志. 北京: 地质出版社，1988. 788 794

(1997-07-21 收稿, 1998-01-04 收修改稿)

\title{
东乌珠穆沁中铁陨石金属相的 场发射扫描电镜研究
}

\author{
毛艳华 王道德 \\ (中国科学院广州地球化学研究所, 广州 510640)
}

摘要 应用高分辨率的场发射扫描电镜对东乌珠穆沁中铁陨石中 $\mathrm{Fe}-\mathrm{Ni}$ 金属相的微结构进行 了研究。表明镍纹石条带具边缘亮边和内部云状花纹带的分带构造特征, 云状花纹带发育典 型的“孤岛一蜂窝”微结构, 孤岛相的大小平均为 $358 \mathrm{~nm}$, 由此估算出东乌珠穆沁中铁陨石在低 温阶段 $\left(<400{ }^{\circ} \mathrm{C}\right)$ 的冷却速率约为 $0.5{ }^{\circ} \mathrm{C} / \mathrm{Ma}$. 通过对金属相中铁纹石和镍纹石 $\mathrm{Ni}$ 浓度分布 剖面的测定, 根据最新的低温 $\mathrm{Fe}-\mathrm{Ni}$ 二元相图, 对东乌珠穆沁中铁陨石的金属相显微结构的成 因进行了详细地探讨.

\section{关键词 场发射扫描电镜 $\mathrm{Fe}-\mathrm{Ni}$ 金属相 微结构 中铁陨石 东乌珠穆沁}

自 70 年代未以来, 在铁陨石、中铁陨石和球粒陨石中发现了镍纹石的带状构造和其他复 杂的精细结构, 并认为是陨石母体在低温条件下经历一系列相转变作用的产物 ${ }^{[1]}$. 陨石金属 相的主要组成为 $\mathrm{Fe}$ 和 $\mathrm{Ni}$, 并含少量的 $\mathrm{Co}, \mathrm{P}, \mathrm{S}$ 和 $\mathrm{C}$, 是研究 $\mathrm{Fe}-\mathrm{Ni}$ 二元体系低温相转变的理想 样品 ${ }^{[2]}$. 近年来, 通过对陨石金属相微结构和微区分析研究, 获得了较完整的 $\mathrm{Fe}-\mathrm{Ni}$ 二元体系 低温阶段 $\left(<400{ }^{\circ} \mathrm{C}\right)$ 的相图 ${ }^{[3]}$. 陨石金属相的微结构研究对冶金学和太空材料科学具重大的 理论价值和实验指导意义.

中铁陨石是一种稀少的陨石类型, 它经历了极为复杂的形成和演化历史 ${ }^{[4]}$. 同其他类型 陨石相比, 中铁陨石的金属相具有粗大的、发育完好的微结构, 因此更有利于对陨石母体低温 热历史进行研究. 目前所获得的中铁陨石冷却速率小于 $1^{\circ} \mathrm{C} / \mathrm{Ma}$, 冷却时间超过 $500 \mathrm{Ma}^{[5]}$. 
最近, 国外学者把高分辨率的场发射扫描电镜( the Field emission scanning electron microscope, FE-SEM) 应用于陨石金属相微结构的研究, 发现中铁陨石中带状镍纹石由边缘亮带 (clear taenite, CT) 和内部云状花纹带 ( cluody zone, CZ) 组成, 而云状花纹带由纳米级大小的孤岛区 (island region) 和蜂窝区( honeycomb region) 构成, 其中孤岛区为镍纹石( y) 基体和马氏体( a2) 沉积物的集合体, 蜂窝区为单一的马氏体 $(\alpha 2)$, 并把孤岛区中孤立相的大小作为指示剂来估 算陨石金属相的低温冷却速率. 如所测得 6 个中铁陨石孤立相的大小为 $387 \sim 469 \mathrm{~nm}$. 据此 估算中铁陨石的冷却速率约为 $0.5^{\circ} \mathrm{C} / \mathrm{M} \mathrm{a}^{[6]}$.

东乌珠穆沁中铁陨石于 1995 年 9 月 7 日 13 时 45 分在我国内蒙古自治区东乌珠穆沁旗 降落, 为目前我国回收到的第二块中铁陨石类型. 本文在该陨石化学组成、岩石学、矿物化学 及稀有气体同位素研究的基础上 ${ }^{[7]}$, 用电子探针 (EPMA) 测定了金属相中铁纹石和带状镍纹 石的 $\mathrm{Ni}$ 浓度分布剖面, 并利用高分辨率的场发射扫描电镜( FE-SEM) 对带状镍纹石的显微结 构进行了研究.

\section{1 实验过程}

从陨石原样中切取小块金属相制成光片. 光片样品首先用于微区成分分析, 在 SMECA SX50 电子探针上作铁纹石和镍纹石的 Ni 浓度分布剖面; 之后, 对光片样品用 $4 \%$ 的苦味酸 (Picral) 溶液蚀刻, 在 500 倍的光学显微镜下观察镍纹石结构, 反复进行抛光和蚀刻, 直到镍纹 石中出现清晰的分带构造. 云状花纹带微结构的研究在 AMARY 1845 场发射扫描电镜上完 成, 在 $30 \mathrm{kV}$ 条件下, 其空间分辨率约为 $1 \mathrm{~nm}$; 而在低工作电压条件下, 电子束的穿透深度要 浅, 能获取更为清晰的表面细节图象 ${ }^{[8]}$. 因此, 本研究中 FE-SEM 的工作电压一般在 $1 \sim 10$ $\mathrm{kV}$, 以便取得清晰的云状花纹带微结构照片.

\section{2 结果与讨论}

东乌珠穆沁中铁陨石金属相发育典型的维氏 台登构造, 并且每条镍纹石都由边缘亮边和内部 云状花纹带组成(图 1). 亮边和云状花纹带界线 清晰( 图 2(a))．云状花纹带发育典型的“孤岛-蜂 窝” 微结构 (island honeycomb structure) (图 2 (b) ), 由孤岛区和蜂窝区二部分交互成网格状, 亮 白色的孤岛 (island) 周围为暗黑色的沟槽 (honeycomb). 从图 2 中可以看出, 整个云状花纹带结构 均匀, 孤岛的大小变化与其位置没有明显的相关 性, 所统计的 16 个孤岛的大小在333 $467 \mathrm{~nm}$ 之 间, 平均大小约为 $358 \mathrm{~nm}$. 根据孤岛相大小与冷 却速率的相关性, 东乌珠穆沁中铁陨石在低温阶 段的冷却速率约为 $0.5{ }^{\circ} \mathrm{C} / \mathrm{Ma}$, 与大多数中铁陨

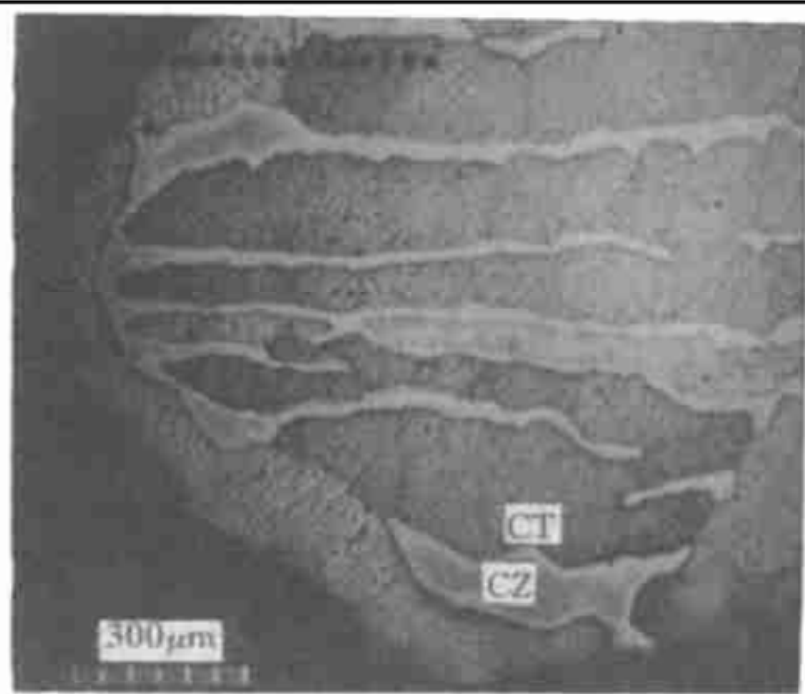

图 1 东乌珠穆沁中铁陨石组构照片 金属相发育维氏台登构造, 而镍纹石具分带结构, 即亮 边 $(\mathrm{CT})$ 和内部云状花纹带 $(\mathrm{CZ})$, 光学显微照片 石冷却速率一样, 都小于 $1{ }^{\circ} \mathrm{C} / \mathrm{Ma}$.

图 3 为该中铁陨石金属相中一条带状镍纹石及相邻铁纹石的 $\mathrm{Ni}$ 浓度分布剖面, 总体上 看, 镍纹石的 $\mathrm{Ni}$ 浓度剖面具典型的“ M” 型分布特征. 铁纹石中 $\mathrm{Ni}$ 的分布均匀, 但在铁纹石/ 

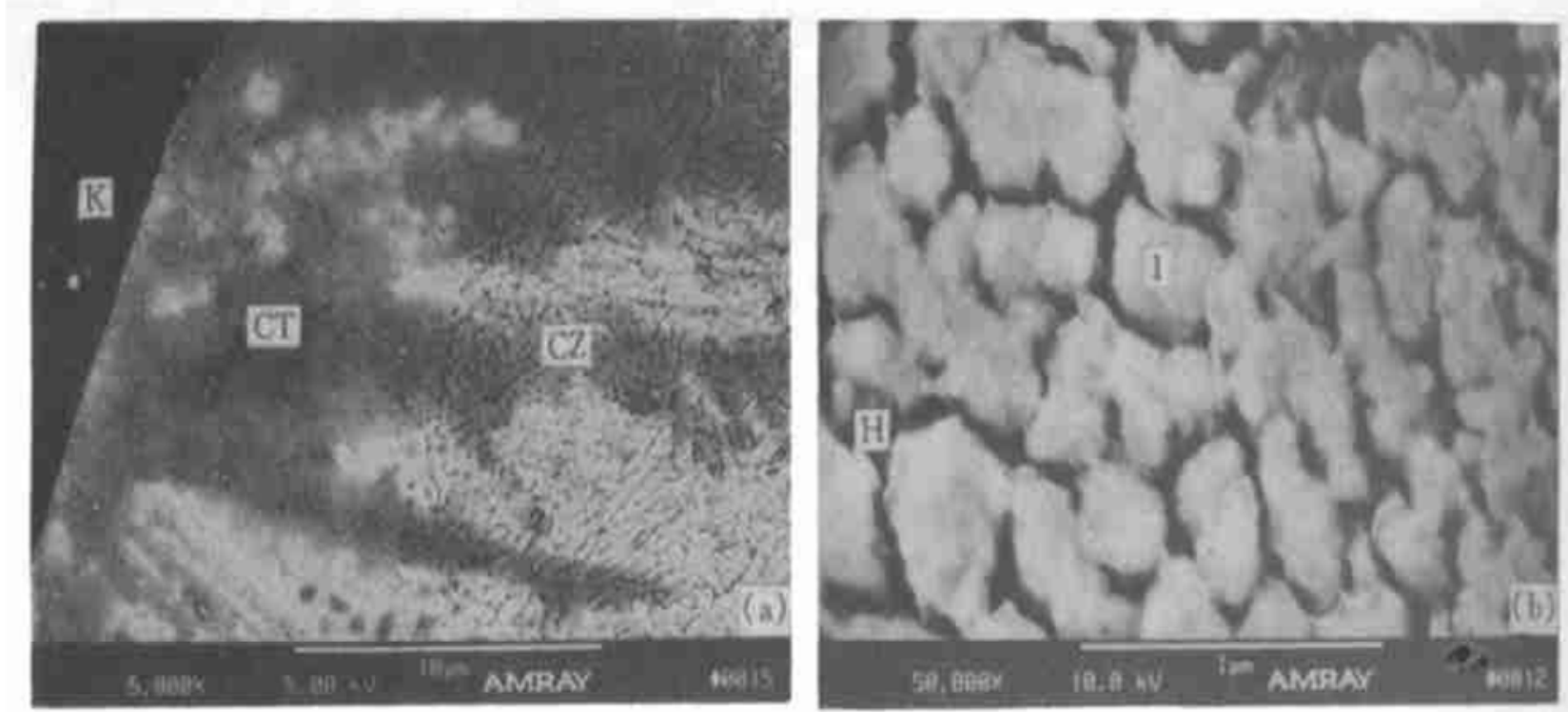

图 2 东乌珠穆沁中铁陨石金属相的 FE-SEM 照片

(a) 低倍数下的带状镍纹石微结构, 左上角为铁纹石 $(\mathrm{K})$, 亮边 $(\mathrm{CT})$ 与铁纹石相邻, 云状花纹带 $(\mathrm{CZ})$ 与亮边界线 清晰; (b) 云状花纹带的高倍数 FE-SEM 图相, 发育典型的“孤岛 (I)-蜂窝 $(\mathrm{H})$ ”微结构, 呈网格状, 结构均匀

镍纹石界面处有明显的亏损, 呈“Agrell”效 应; 表明陨石母体中金属相经历了缓慢的结 晶作用过程 ${ }^{[9]}$. 带状镍纹石亮边 $(\mathrm{CT})$ 的 $\mathrm{Ni}$ 浓度自铁纹石/镍纹石界面处的 $54.1 \%$ 向内 逐渐下降到 CT/ CZ 交界面处的 $48.5 \%$; 而云 状花纹带 $(\mathrm{CZ})$ 具有均一的 $\mathrm{Ni}$ 含量 (约为 $43 \%)$, 浓度剖面平坦. 镍纹石 $\mathrm{Ni}$ 浓度剖面 间断点位于 CT/ CZ 交界面上. 这种 $\mathrm{Ni}$ 浓度 分布特征与 $\mathrm{Fe}-\mathrm{Ni}$ 体系的低温相变有关 ${ }^{[3]}$, 表明东乌珠穆沁中铁陨石金属相经历了高温 成核结晶作用阶段并形成维氏台登构造后, 在低温阶段发生相变反应, 形成了镍纹石内 的分带构造及相应的 $\mathrm{Ni}$ 浓度分布剖面间断 点. 另外, 镍纹石核部 $\mathrm{Ni}$ 浓度剖面平坦的特

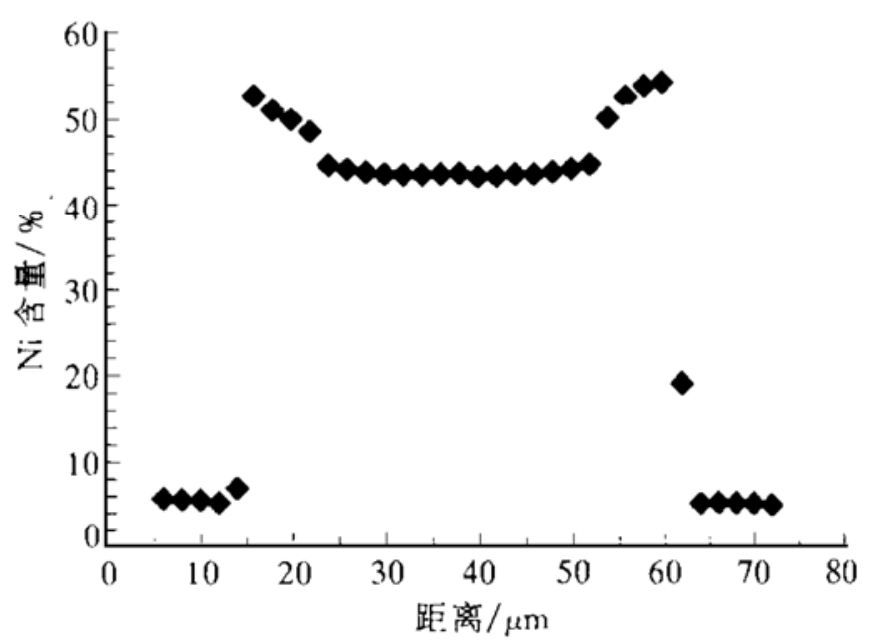

图 3 东乌珠穆沁中铁陨石带状镍纹石的电子 探针 $\mathrm{Ni}$ 浓度分布剖面 征表明东乌珠穆沈中铁陨石金属相经历了相当缓慢的低温冷却历史, $\mathrm{Ni}$ 在镍纹石内的扩散作 用达到或接近平衡.

东乌珠穆沁中铁陨石镍纹石内分带构造是母体在低温阶段下缓慢冷却过程中发生各种相 转变的产物. 根据目前研究成果所获得的 $\mathrm{Fe}-\mathrm{Ni}$ 二元相图 (图 4), 当陨石冷却到大约 $900{ }^{\circ} \mathrm{C}$ 时, $\mathrm{Fe}-\mathrm{Ni}$ 二元体系发生固熔体平衡转变反应: $\gamma \vec{a}+\gamma$, 铁纹石 $(\alpha-b c c)$ 相在镍纹石 $(\gamma-f c c)$ 基体内 发生成核作用并析出. 这种成核析出是受 $\mathrm{Ni}$ 在镍纹石内的扩散作用控制的, 当体系温度下降 时, $\mathrm{Ni}$ 在 $\gamma$ 基体内的扩散作用越来越慢, 结果 $\mathrm{Ni}$ 在靠近 $\alpha / \gamma$ 交界面的 $\gamma$ 相边沿不断堆积. 因 此形成了镍纹石的“ $\mathrm{M}$ ” 型 $\mathrm{Ni}$ 浓度分布剖面, 二相交界面处的 $\mathrm{Ni}$ 含量分别由相图中 $\alpha / \alpha+\gamma$ 和 


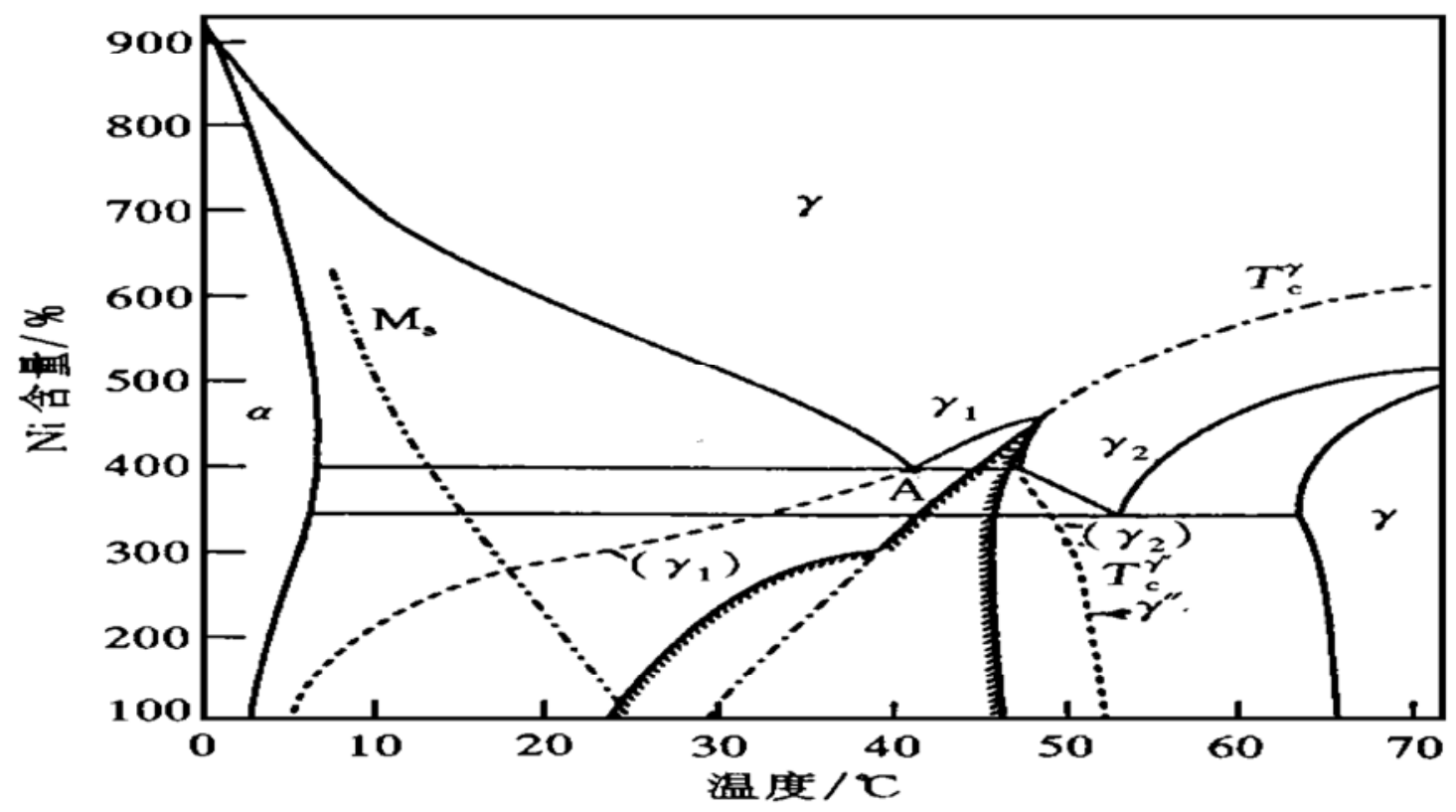

图 4 由陨石金属相微结构研究获取的 $\mathrm{Fe} \mathrm{Ni}$ 相图( 据文献[3])

$a$ 一贫 $\mathrm{Ni}$ 体心 $\mathrm{FeNi}$ (铁纹石), $\mathrm{r}$ 一一富 $\mathrm{Ni}$ 面心 $\mathrm{FeNi}$ (镍纹石), $\mathrm{r} 1$ 一一贫 $\mathrm{Ni}$ 面心顺磁性镍纹石, $\mathrm{r} 2$ 一一富 $\mathrm{Ni}$ 面 心铁磁性镍纹石; $\gamma^{\prime}$ 一有序 $\mathrm{Ni}_{3} \mathrm{Fe}$ 相, $\gamma^{\prime \prime}$ 一有序 $\mathrm{FeNi}$ 相; $\mathrm{Ms}$ 一马体相转变点; $T_{\mathrm{c}}^{\gamma}$ 一一镍纹石相的居里温 度, $T_{\mathrm{c}}^{\mathrm{C}^{\prime \prime}}$ 一一富 $\mathrm{Ni} \gamma^{\prime \prime}$ 相的有序化温度, $\mathrm{A}$ 一一三相点

$\alpha+\gamma / \gamma$ 固熔体曲线决定. 在大约 $400{ }^{\circ} \mathrm{C}$ 时, 体系内发生偏析反应 (montectoid reaction), $\gamma 1{ }^{\rightarrow} a$ $+\mathrm{r} 2$; 例如, 在 $389^{\circ} \mathrm{C}$ 含 $\mathrm{Ni} 41.2 \%$ 的三相点 $\mathrm{A}$ 的偏析反应为

$$
\begin{gathered}
\gamma 1(41.2 \% \mathrm{Ni}) \leftarrow(6.6 \% \mathrm{Ni})+ \\
\gamma 2(47.5 \% \mathrm{Ni})
\end{gathered}
$$

由于发生偏析反应, 镍纹石条带的 $\mathrm{Ni}$ 浓度剖面在 41\% 48\% 之间出现间断点(图 3), 形成高 $\mathrm{Ni}(>48 \%)$ 的区域和低 $\mathrm{Ni}(<41 \%)$ 的区域, 因此镍纹石条带出现分带构造 ${ }^{[1,10]}$. 在偏析反应 中形成的高 Ni 区域, 由超饱和的固熔体结构 82 相组成, 并经缓慢的低温冷却过程, 它对应于 镍纹石亮边 (clear taenite) ; 东乌珠穆沁中铁陨石的镍纹石边缘亮边 $\mathrm{Ni}$ 含量为 $48.455 \% \sim 54$. 123\%。而偏析反应中形成的低 Ni 区域对应于镍纹石的云状花纹带 (cloudy zone), 它将经历 更为复杂的低温相变作用.

当 $\mathrm{Fe}-\mathrm{Ni}$ 固熔体体系冷却到低于 $400{ }^{\circ} \mathrm{C}$ 时, 开始出现连续的 $\gamma 1+\gamma 2$ 混溶间隙区 (miscibility gap), 准稳定的相边界 $\gamma 1$ 和 $\gamma 2$ 由虚线段表示 (图 4). 在低于大约 $350{ }^{\circ} \mathrm{C}$ 时, 镍纹石内部云 状花纹带进入到旋节线区域( spinodal region, 即图 4 中的阴影线区域), 镍纹石相变分解成 $\mathrm{r} 1$ 和 $\gamma 2$, 其 $\mathrm{Ni}$ 含量分别由混溶间隙区的低 $\mathrm{Ni}$ 边界 ( $\mathrm{\gamma} 1$ ) 和高 $\mathrm{Ni}$ 边 ( r2) 确定. 富 $\mathrm{Ni}$ 区的 $\mathrm{\gamma} 2$ 相构 成云状花纹带的孤岛区, 而贫 Ni 区的 $\gamma 1$ 相构成蜂窝区, 形成云状花纹带的“孤岛-蜂窝”微结 构. 随着缓慢冷却的继续进行, 富 $\mathrm{Ni}$ 的孤岛相 $\mathrm{\gamma} 2$ 经历有序化转变作用, 其 $\mathrm{Ni}$ 含量不断得到 富集, 而贫 $\mathrm{Ni}$ 的蜂窝相 $\mathrm{r} 1$ 的 $\mathrm{Ni}$ 含量则沿着固熔体曲线不断降低. 大约 $260{ }^{\circ} \mathrm{C}$ 时, 在混溶间 隙区与马氏体相转变点 $(\mathrm{Ms})$ 交汇处, 蜂窝相 81 发生相转变反应形成马氏体 ( a 2-martensite). 在已研究过的其他中铁陨石中, 富 $\mathrm{Ni}$ 的亮边和孤岛相内部出现大量暗色溶蚀凹坑, 为相变反 应形成的马氏体沉积物 ( a2 $)^{[3]}$, 即在旋节线区域之外, 混溶间隙区中富 $\mathrm{Ni}$ 固溶体曲线( r2) 之 间( 46\% 52\%), 富 $\mathrm{Ni}$ 的超饱和固熔体( $\mathrm{\gamma} 2$ ) 内发生 $\mathrm{Ni}$ 的进一步富集作用, 形成低 $\mathrm{Ni}$ 的沉积 
物( $\alpha 2$ ) 和富 $\mathrm{Ni}$ 的基体. 但是, 对于东乌珠穆沁中铁陨石, 镍纹石的亮边 (CT) 和云状花纹带 (CZ) 内的孤岛相都光亮平滑, 没有因沉积物的溶蚀而出现凹坑. 这表明东乌珠穆沁中铁陨石 在母体内比其他中铁陨石经历了更为缓慢的低温冷却过程; 或者, 在同一母体中它比其他中铁 陨石埋藏更深.

\section{3 结论}

(1) 应用高分辨率的场发射扫描电镜研究了东乌珠穆沁中铁陨石 $\mathrm{Fe}-\mathrm{Ni}$ 金属相的微结 构. 镍纹石条带具边缘亮边和内部云状花纹带的分带构造特征, 云状花纹带发育典型的“孤岛 一蜂窝” 微结构( island honeycomb microstructure). 孤岛相的大小平均为 $358 \mathrm{~nm}$, 冷却速率约为 $0.5{ }^{\circ} \mathrm{C} / \mathrm{Ma}$. 另外, 东乌珠穆沁中铁陨石中带状镍纹石的亮边和孤岛相内未出现马氏体沉积 物, 这与其母体经历了缓慢的低温 $\left(<400{ }^{\circ} \mathrm{C}\right.$ ) 冷却历史是一致的.

(2) 东乌珠穆沁中铁陨石金属相中带状镍纹石的 $\mathrm{Ni}$ 浓度剖面具典型的“ M”型分布特征. 铁纹石/ 镍纹石界面有明显的“Agrell” 效应。镍纹石带内 CT/ CZ 交界处出现 Ni 浓度分布的间 断点. 镍纹石亮边的 $\mathrm{Ni}$ 浓度自边缘的 $54.1 \%$ 向内逐渐下降到 $48.5 \%$; 而云状花纹带的 $\mathrm{Ni}$ 含 量均匀, 约为 $43 \%$ 。带状镍纹石的 $\mathrm{Ni}$ 浓度剖面特征表明, 东乌珠穆沁中铁陨石金属相经历了 高温成核结晶作用阶段 $\left(900 \sim 400{ }^{\circ} \mathrm{C}\right)$ 之后, 在低温阶段 $\left(<400{ }^{\circ} \mathrm{C}\right)$ 缓慢冷却, 并伴随复杂的低 温相变反应.

致谢 瑞士伯尔尼大学矿物研究所 Larry Diamond 博士协助镍纹石 $\mathrm{Ni}$ 浓度分布剖面的测定; 场发射扫描电镜 微结构研究是在中国核动力研究设计院材料研究所完成的; 样品的制备和实验过程中得到潘英、李卫军二位 高级工程师很多帮助; 林扬挺博士审阅了全文并提出了许多宝贵意见, 谨在此一并致谢. 本文工作为国家自 然科学基金( 批准号: 49772098) 资助项目。

\section{参 考 文 献}

1 Scott E R D, Clarke R S Jr. Identification of clear taenite in meteorites as ordered FeNi. Nature, 1979, 281: $360 \sim 362$

2 Reuter K B, Williams D B, Goldstein J I. Determination of the Fe Ni phase diagram below $400{ }^{\circ} \mathrm{C}$. M etall Trans, 1989 , 20A: $719 \sim 725$

3 Yang C W, Williams D B, Goldstein J I. A revision of the Fe Ni phase digram at low temperatures $\left(<400^{\circ} \mathrm{C}\right)$. Joural of Phase Equilibria, 1996, 17: 522 531

4 Rubin A E. A history of the mesosiderite asteroid. American Sceintist, 1997, 85: 26 35

5 Pow ell B N. Petrology and chemistry of mesosiderite iv. Textures and composition of nicker iron. Geochim Cosmochim Acta, 1969, 33: 789 810

6 Yang C W, Williams D B, Goldstein J I. A new empirical cooling rate indicator for meteorites based on the size of the cloudy zone of the metallic phases. Meteoritics, 1997, 32: 423 429

7 毛艳华, 王道德, 陶克捷等. 东乌珠穆沁及渭源中铁陨石岩石学特征及分类. 地球化学, 1998,

8 Paw ley J B. Low voltage scanning electron microscopy. J M icroscopy, 1984, 136: 45 68

9 Agrell S O, Long J V, Ogilvie R E. Nickel content of kamacite near the interface with taenite in iron meteorites. Nature, 1963, 198: 349

10 Reuter K B, Williams D B, Goldstein J I. Low temperature phase transformations in the metallic phases of iron and stony-iron meteorites. Geochim Cosmochim Acta, 1988, 52: 617 626 